\title{
The use of tranexamic acid in reducing bleeding complications
}

Steve Chaplin

Tranexamic acid inhibits fibrinolysis by competitively blocking the lysine binding sites of plasminogen, inhibiting binding between fibrin and plasminogen, and activation of plasminogen. It also competitively inhibits tissue plasminogen activator and inhibits plasmininduced platelet activation. The synthesis of tranexamic acid was first reported in 1962 . It is used to treat or prevent excessive blood loss from trauma, surgery, and in various medical conditions including haemophilia and heavy menstrual bleeding. As a medicine affecting coagulation, it is listed in the World Health Organization's List of Essential Medicines. Tranexamic acid remains a versatile and inexpensive agent with potential benefit in health services from the lowest to highest income countries. This pharmacy review focuses on the evidence base to support the use of tranexamic acid in acquired and inherited bleeding disorders to reduce bleeding complications.

Keywords: tranexamic acid, antifibrinolytic

Tranexamic acid is the trans isomer of $\mathrm{p}$-aminomethyl cyclohexane carboxylic acid (Figure 1; C8H15NO2; molecular weight 157 [1,2]). It is a white or almost crystalline powder, freely soluble in water and glacial acetic acid, but practically insoluble in acetone or ethanol. The original report on the synthesis of tranexamic acid was published by Okamoto and Okamoto in 1962 [50].

Pharmacokinetics

After oral administration of 10 or $100 \mathrm{mg} / \mathrm{kg}$ (the normal therapeutic dose is $15-25 \mathrm{mg} / \mathrm{kg}$ ), peak serum concentrations of $2 \mathrm{mg} / \mathrm{l}$ and $40 \mathrm{mg} / \mathrm{l}$ respectively occur at approximately 3 - 4 hours [1]. Bioavailability is approximately $40 \%$.

The distribution of tranexamic acid is described by a twocompartment pharmacokinetic model [1,3]. Plasma protein binding at therapeutic levels is about $3 \%$ and is due to binding to plasminogen; it does not bind to serum albumin. The volume of distribution is $9-12$ litres $[3,4]$. Tranexamic acid diffuses rapidly into joint fluid and the synovial membrane, achieving concentrations similar to serum levels; the biological half-life in joint fluid is approximately 3 hours $[1,4]$.

Steve Chaplin, medical writer Email: stevechaplin504@gmail.com
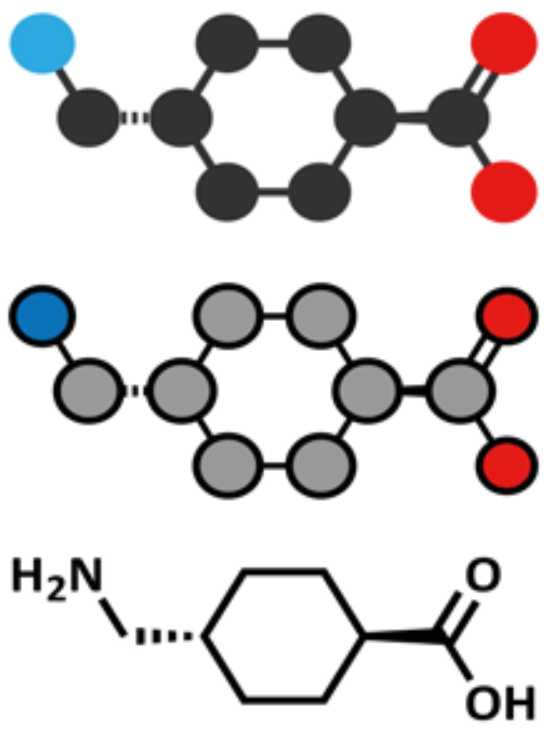

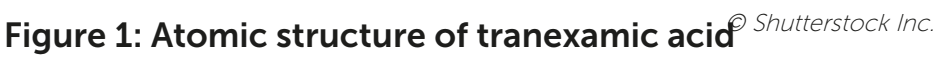

Tranexamic acid does not undergo metabolism and is excreted unchanged, predominantly in urine [4].

Tranexamic acid is excreted by glomerular filtration. Renal clearance in adults has been estimated at $80 \mathrm{ml} / \mathrm{min} / 70 \mathrm{~kg} 3$ (in patients undergoing cardiopulmonary bypass) and 110 - $116 \mathrm{~m} / \mathrm{min}$ (not adjusted for body mass) [4]. In children with a mean age of 0.56, 5.5 and 36 months undergoing cardiopulmonary bypass, clearance was estimated at approximately 40, 84 and $170 \mathrm{ml} / \mathrm{min}$ [5].

The elimination half-life is about 3 hours in adults [4] and 1 2 hours in infants and children [5]. After a single intravenous dose of $10 \mathrm{mg} / \mathrm{kg}$ in adults, about $30 \%$ was recovered in the urine in the first hour, 55\% up to 3 hours and $90 \%$ within 12 -24 hours $[1,4]$. After oral administration of $10-15 \mathrm{mg} / \mathrm{kg}$ in adults, about $40 \%$ of the dose was recovered in the urine within 24 hours $[1,4]$. Plasma concentrations of tranexamic acid are increased in patients with renal insufficiency.

Mechanism of action and pharmacodynamic effects Tranexamic acid inhibits fibrinolysis by competitively blocking the lysine binding sites of plasminogen, inhibiting binding between fibrin and plasminogen, and activation of plasminogen. It also competitively inhibits tissue plasminogen activator and inhibits plasmin-induced platelet activation $[6,7]$. In experimental models, tranexamic 
acid inhibits fibrinolysis over the concentration range 10 - $100 \mathrm{micromol} / \mathrm{l}$ and reduces bleeding time [8]. Adding tranexamic acid to recombinant FVIIa or FVIII increases clot stability to a much greater extent than the factors alone $[9,10]$.

\section{Formulations}

There are many brands of tranexamic acid available globally. For example, it is marketed in the United States and Australia as Lysteda tablets, and as Cyklokapron and Transamin intravenous injection; in the UK as Cyklokapron (tablets and IV injection), Cyklo-F, Menstralite and Femstrual (all tablets); in Asia as Transcam (tablets); in Bangladesh as Traxyl (capsules, IV injection); in India as Pause (tablet); in South America as Espercil (capsule, IV injection); in Japan as Nicolda (tablets); in France and Romania as Exacyl (IV injection); and in Egypt as Kapron (tablets, IV injection). A capsule formulation is marketed in the Philippines as Hemostan and as Hexakapron in Israel [2]. Some brands are intended for prescription use only, others for overthe-counter or online sale. In Uganda, tranexamic acid is available as Transamin injection, Transamin 250 and 500mg tablets, Hemsamic 500mg tablets, Tranlok 500mg tablets and Tranlok injection [11]. There are also many generic formulations of oral and intravenous preparations; for example, Medlndia's database lists 95 generic formulations manufactured by 65 companies [12].

\section{Stability and storage}

Information about correct storage for most formulations is not readily available. For the Cyklokapron brand, marketed by Pfizer in the UK, the Summary of Product Characteristics (SPC) for the injection states that its shelf life is 3 years; it does not recommend a temperature range for storage, but adds that it should not be frozen [13]. In the US, where Cyklokapron is marketed jointly by Pfizer and Pharmacia \& Upjohn, the product labelling states that the injection should be stored at $25^{\circ} \mathrm{C}$, but excursions are permitted within the range $15-30^{\circ} \mathrm{C}$ [14]. A US study has shown that tranexamic acid injection is stable for 12 weeks at temperatures of $-20^{\circ} \mathrm{C}, 4^{\circ} \mathrm{C}, 22^{\circ} \mathrm{C}$ and $50^{\circ} \mathrm{C}$, although the ampoules broke when the solution froze [15].

The ampoules are for single use. The chemicophysical stability of the solution is at least 24 hours at $25^{\circ} \mathrm{C}$, but the solution contains no preservative and sterility cannot be assured after opening [13]. Cyklokapron injection can be mixed with most solutions for infusion (e.g. electrolyte, carbohydrate, amino acid and dextran solutions); heparin may be added to Cyklokapron injection [13]. If the injection is mixed with other products for intravenous administration, tranexamic acid is stable for up to 4 hours at room temperature [16]. Cyklokapron injection should not be mixed with blood or solutions containing a penicillin $[13,16]$.

The UK SPC for Cyclokapron tablets states that the shelf life is 5 years; the tablets should be stored below $25^{\circ} \mathrm{C}$ [17]. In the US, Ferring Pharmaceuticals advise that Lysteda tablets should be stored at $15-30^{\circ} \mathrm{C}[16]$. The same recommended temperature range is cited by MedIndia for the storing of both tablet and injection formulations [18], suggesting they are applicable globally. Differences in these recommended temperature ranges may reflect local custom and practice rather than evidence of stability.

No special disposal requirements have been found.

Although many online sites sell tranexamic acid, no reports of counterfeits of products intended for therapeutic use have been found (at least in the English language).

Tranexamic acid appears to be an ingredient in skinwhitening products and online postings suggest a degree of concern about fake formulations. However, it is unclear whether this is an important issue and online comments cannot be independently verified.

\section{Indications and doses}

The indications and doses licensed in the UK $[13,17]$ have been used for the purpose of this review, on the basis that the data are reliable and the disposition of tranexamic acid is not affected by ethnicity.

\section{Licensed indications in the UK}

Cyklokapron tablets are licensed for short-term use for haemorrhage or risk of haemorrhage in increased fibrinolysis or fibrinogenolysis, and local fibrinolysis as it occurs in prostatectomy and bladder surgery, menorrhagia, epistaxis, conisation of the cervix, traumatic hyphaema and hereditary angioneurotic oedema. Of specific relevance to this paper, the tablets are also licensed for the 'management of dental extraction in haemophiliacs' [17].

Cyklokapron injection is not specifically licensed for an indication in people with haemophilia, but nor are they excluded. The licensed indications are: haemorrhage caused by general or local fibrinolysis (such as menorrhagia and metrorrhagia), gastrointestinal bleeding, haemorrhagic urinary disorders further to prostate surgery or surgical procedures affecting the urinary tract, surgery (specifically adenoidectomy, tonsillectomy, dental extractions; gynaecological or disorders of obstetric origin; thoracic, abdominal and other major surgical intervention such as cardiovascular surgery), and the management of haemorrhage due to the administration of a fibrinolytic agent [13].

\section{Dosage}

The recommended oral dose for the management of dental extraction in people with haemophilia is $2-3500 \mathrm{mg}$ tablets every 8 hours (based on a dose of $25 \mathrm{mg} / \mathrm{kg} /$ day).

The recommended intravenous dose as the standard treatment of local fibrinolysis is $0.5-1.0 \mathrm{~g}$ by slow IV injection (at the rate of $1 \mathrm{ml} /$ minute) $2-3$ times daily. For general fibrinolysis, the recommended dose is $1.0 \mathrm{~g}$ by slow IV injection every $6-8$ hours, which is equivalent to $15 \mathrm{mg} /$ $\mathrm{kg}$.

\section{Contraindications and prescribing cautions}

All contraindications and prescribing cautions listed in UK 
Table 1: Contraindications and precautions listed in UK SPCs for Cyklokapron tablets [17]

\section{Contraindications \\ Precautions}

Hypersensitivity to tranexamic acid or any of the other ingredients

Severe renal impairment (risk of accumulation)

Active thromboembolic disease

History of venous or arterial thrombosis

Fibrinolytic conditions following consumption coagulopathy

History of convulsions
In case of haematuria of renal origin (especially in haemophilia), there is a risk of mechanical anuria due to formation of a ureteral clot.

In the long-term treatment of patients with hereditary angioneurotic oedema, regular eye examinations (e.g. visual acuity, slit lamp, intraocular pressure, visual fields) and liver function tests should be performed.

Patients with irregular menstrual bleeding should not use Cyklokapron until the cause of irregular bleeding has been established. If menstrual bleeding is not adequately reduced by Cyklokapron, an alternative treatment should be considered. Clinical experience with Cyklokapron in menorrhagic children under 15 years of age is not available.

Tranexamic acid should be administered with care in patients receiving oral contraceptives because of the increased risk of thrombosis.

Patients with a previous thromboembolic event and a family history of thromboembolic disease (patients with thrombophilia) should use Cyklokapron only if there is a strong medical indication and under strict medical supervision.

Blood levels are increased in patients with renal insufficiency; a dose reduction is therefore recommended.

The use of tranexamic acid in cases of increased fibrinolysis due to disseminated intravascular coagulation is not recommended.

Patients who experience visual disturbance should be withdrawn from treatment.
SPCs for Cyklokapron tablets and injections are shown in Tables 1 and 2; it should be noted that some are not relevant to people with haemophilia.

\section{Age}

No dose adjustment is recommended for older people, except according to renal function.

Therapeutic experience is limited in children. The recommended oral dose is $25 \mathrm{mg} / \mathrm{kg}$ per dose. The recommended intravenous dose is $20 \mathrm{mg} / \mathrm{kg} /$ day.

\section{Renal impairment}

The use of tranexamic acid is contraindicated in patients with severe renal impairment. The oral dose should be reduced to $15 \mathrm{mg} / \mathrm{kg}$ twice daily in patients with mild renal impairment (serum creatinine 120 - 249micromol/l) and to $15 \mathrm{mg} / \mathrm{kg}$ once a day in moderate renal impairment (serum creatinine 250 - 500micromol/l). For patients with mild to moderate renal impairment, the intravenous dose is adjusted according to the serum creatinine level, as shown in Table 3.

Table 3: Dose adjustments needed for IV tranexamic acid

\begin{tabular}{|l|l|l|}
$\begin{array}{l}\text { Serum creatinine } \\
\text { (micromol/l) }\end{array}$ & $\begin{array}{l}\text { Dose } \\
\text { (mg/kg) }\end{array}$ & \multicolumn{1}{l|}{ Frequency } \\
\hline 120 to 249 & 10 & 12 -hourly \\
\hline 250 to 500 & 10 & 24 -hourly \\
\hline$>500$ & 5 & 24 -hourly \\
\hline
\end{tabular}

\section{Hepatic impairment}

No dose adjustment is recommended for people with hepatic impairment. This is explicitly stated only for the injection in UK guidance, but should also apply to the oral formulation.

\section{Pregnancy and breastfeeding}

There is no evidence from animal studies that tranexamic acid is teratogenic. However, it crosses the placenta and is present in cord blood at concentrations equal to blood levels [16]. There is a lack of evidence showing that it is safe to take during the first trimester. There is no evidence that its use in women during the second and third trimesters is associated with adverse outcomes.

In the US, tranexamic acid is classed as Pregnancy (Category B), i.e. 'Animal reproduction studies have failed to demonstrate a risk to the foetus and there are no adequate and well-controlled studies in pregnant women' [19].

In the UK, Pfizer recommends that women of childbearing potential must use effective contraception during treatment with the injection, and that its use is not recommended during the first trimester. For the tablets, it recommends only that 'usual caution... should be observed'.

There is no evidence that tranexamic acid affects fertility.

Tranexamic is excreted in breast milk at a concentration of $1 \%$ of the concurrent blood level after oral administration. An antifibrinolytic effect is unlikely. Pfizer in the UK recommends avoiding breastfeeding during treatment with the injection. In the US, Pfizer and Pharmacia \& Upjohn 
Table 2: Contraindications and precautions listed in UK SPCs for Cyklokapron injections [13]

\section{Contraindications \\ Precautions}

Hypersensitivity to the active substance or to any of the excipients (note: the only component other than tranexamic acid is water for injection)

Acute venous or arterial thrombosis

Fibrinolytic conditions following consumption coagulopathy except in those with predominant activation of the fibrinolytic system with acute severe bleeding

Severe renal impairment (risk of accumulation)

History of convulsions

Intrathecal and intraventricular injection, intracerebral application (risk of cerebral oedema and convulsions)

US labelling contraindicates tranexamic acid in patients with subarachnoid haemorrhage -anecdotal experience suggests it may cause cerebral oedema and cerebral infarction14
Intravenous injections should be given very slowly.

Tranexamic acid should not be administered by the intramuscular route.

\section{Convulsions}

Cases of convulsions have been reported in association with tranexamic acid treatment. In coronary artery bypass graft (CABG) surgery, most of these cases were reported following intravenous injection of tranexamic acid in high doses. With the use of the recommended lower doses of tranexamic acid, the incidence of postoperative seizures was the same as that in untreated patients.

\section{Visual disturbances}

Attention should be paid to possible visual disturbances, including visual impairment, blurred vision and impaired colour vision. If necessary, the treatment should be discontinued. With continuous long-term use of tranexamic acid solution for injection, regular ophthalmologic examinations (eye examinations, including visual acuity, colour vision, fundus, visual field, etc.) are indicated. With pathological ophthalmic changes, particularly with diseases of the retina, the physician must decide after consulting a specialist on the necessity of long-term use of tranexamic acid solution for injection in each individual case.

\section{Haematuria}

In case of haematuria from the upper urinary tract, there is a risk of ureteric obstruction.

\section{Thromboembolic events}

Risk factors of thromboembolic disease should be considered before the use of tranexamic acid. In patients with a history of thromboembolic disease or in those with increased incidence of thromboembolic events in their family history (patients with a high risk of thrombophilia), tranexamic acid solution for injection should only be administered if there is a strong medical indication after consultation with a physician experienced in haemostaseology and under strict medical supervision.

Tranexamic acid should be administered with care in patients receiving oral contraceptives due to the increased risk of thrombosis.

\section{Disseminated intravascular coagulation}

Patients with disseminated intravascular coagulation (DIC) should not, in most cases, be treated with tranexamic acid. If tranexamic acid is given, it should be restricted to those in whom there is predominant activation of the fibrinolytic system with acute severe bleeding. Characteristically, the haematological profile approximates to the following:

Reduced euglobulin clot lysis time prolonged prothrombin time reduced plasma levels of fibrinogen, factors $\mathrm{V}$ and VIII, plasminogen fibrinolysin and alpha-2 macroglobulin

normal plasma levels of P and P complex, i.e. factors II (prothrombin), VIII and X increased plasma levels of fibrinogen degradation products

a normal platelet count

The foregoing presumes that the underlying disease state does not, of itself, modify the various elements in this profile. In such acute cases, a single dose of $1 \mathrm{~g}$ tranexamic acid is frequently sufficient to control bleeding. Administration of tranexamic acid in DIC should be considered only when appropriate haematological laboratory facilities and expertise are available. advise caution [16]. A case-control study of outcomes in 21 women taking tranexamic acid while breastfeeding reported no acute adverse effects on the infant and no developmental effects [20].

\section{Drug interactions}

Other than interfering with the effects of fibrinolytic drugs, tranexamic acid has no clinically significant drug interactions.

\section{Sources of evidence of efficacy}

The medical and surgical risks associated with haemophilia 
are summarised in the 2012 update of the World Federation of Hemophilia (WHF) guideline [21]. A large number of clinical trials evaluating the efficacy of tranexamic acid have been published, but few prospective randomised comparative trials have involved people with haemophilia, in whom the balance of risk and benefit is fundamentally different from that in people with no bleeding disorder. This section summarises recent relevant evidence by indication, beginning with a precis of the WHF recommendations for the use of tranexamic acid.

\section{WHF guideline [21]}

The WHF recommendations for use of tranexamic acid are summarised in Appendix 1. Where WHF makes statements about clinical practice, it specifies the level of supporting evidence in which treatment benefits and harms are rated on a scale from 1 (best) to 5 (worst). Most of the evidence supporting the recommended indications for tranexamic acid is level 4 or 5. Full details are available at www.cebm. net/ocebm-levels-of-evidence.

\section{Dental or oral surgery (meta-analysis)}

A Cochrane systematic review identified only one randomised controlled trial of tranexamic acid to prevent bleeding in people with haemophilia undergoing oral or dental surgery among 313 publications retrieved in a comprehensive literature search carried out in September and December $2015[9,23]$. The findings of this trial, which was reported in 1972 and was based on data collected in the 1960s, are summarised in Appendix 2. There were no eligible publications involving people with von Willebrand disease.
The appraisal of the trial concluded it was of moderate quality, largely due to its small size and incomplete documentation of randomisation and blinding. This trial suggested that, compared with placebo, 1.5 patients would need to be treated with tranexamic acid to prevent one case of postoperative bleeding.

Publications that do not meet the eligibility criteria for the Cochrane review include two small randomised controlled trials, [24,25], four retrospective studies [26-29], one casecontrol study [30], and two case series [31,32]. These studies evaluated the effectiveness of a mouthwash to prevent bleeding from tooth descaling $[24,25]$, compression with tranexamic acid [28], prophylaxis with tranexamic acid $[26,27,30]$, perioperative use $[31,32]$, or an unspecified regimen [29]. In several studies, tranexamic was not the only haemostatic agent used.

\section{Surgery}

A Cochrane systematic review (search date November 2014) identified no comparative randomised trials of sufficient quality for the use of tranexamic acid for bleeding prevention during surgery in people with haemophilia or other congenital bleeding disorders (other than that cited in the review of dental procedures above) [33].

Two papers were published after the literature search for the systematic review was carried out. One reviewed evidence for combining tranexamic acid and anti-inhibitor coagulant complex (AICC) in patients with inhibitors [34]. This combination is potentially synergistic and may increase clot stability, but it may also be associated with an increased risk of thrombotic events and disseminated intravascular coagulation. The authors found no reports of thrombotic

Table 4: Adverse effects listed by the current UK SPCs for Cyklokapron tablets (17) and injection [17]

\begin{tabular}{|c|c|c|}
\hline & Tablets [17] & Injection [13] \\
\hline $\begin{array}{l}\text { Immune system } \\
\text { disorders }\end{array}$ & $\begin{array}{l}\text { Very rare: Hypersensitivity reactions, including } \\
\text { anaphylaxis }\end{array}$ & $\begin{array}{l}\text { Frequency not known: Hypersensitivity reactions, including } \\
\text { anaphylaxis }\end{array}$ \\
\hline Eye disorders & $\begin{array}{l}\text { Rare: Colour vision disturbances, retinal/artery } \\
\text { occlusion }\end{array}$ & $\begin{array}{l}\text { Frequency not known: Visual disturbances, including im- } \\
\text { paired colour vision }\end{array}$ \\
\hline Vascular disorders & $\begin{array}{l}\text { Rare: Thromboembolic events } \\
\text { Very rare: Arterial or venous thrombosis at any } \\
\text { sites }\end{array}$ & $\begin{array}{l}\text { Frequency not known: Malaise with hypotension, with or } \\
\text { without loss of consciousness (generally following a too fast } \\
\text { intravenous injection, exceptionally after oral administration). } \\
\text { Arterial or venous thrombosis at any sites. }\end{array}$ \\
\hline $\begin{array}{l}\text { Gastro-intestinal } \\
\text { disorders }\end{array}$ & $\begin{array}{l}\text { Very rare: Digestive effects, such as nausea, } \\
\text { vomiting and diarrhoea, may occur but } \\
\text { disappear when the dosage is reduced. }\end{array}$ & Common: Diarrhoea, vomiting, nausea \\
\hline $\begin{array}{l}\text { Skin and subcu- } \\
\text { taneous tissue } \\
\text { disorders }\end{array}$ & Rare: Allergic skin reactions & Uncommon: Dermatitis allergic \\
\hline $\begin{array}{l}\text { Nervous system } \\
\text { disorders }\end{array}$ & - & $\begin{array}{l}\text { Frequency not known: Convulsions, particularly in case of } \\
\text { misuse }\end{array}$ \\
\hline
\end{tabular}


events and concluded: 'concomitant therapy with AICC and tranexamic acid can be considered when haemophilia patients with inhibitors undergo dental or surgical procedures to reduce blood loss and avoid life threatening bleeding. Furthermore, concomitant use of AICC and tranexamic acid should be considered for patients with bleeding who have failed monotherapy with either AICC or rFVIIa.'

However, evidence was based on low numbers of patients for some indications, and there is a need for further randomised controlled trials to provide stronger evidence.

An older, non-comparative study described treatment with the combination of tranexamic acid and APCC in a total of eight patients with congenital haemophilia with inhibitors or acquired haemophilia [35]. The haemostatic outcome was rated excellent or good in 10 of 11 treatments and poor in one. There were no episodes of arterial, venous thrombosis or disseminated intravascular coagulation, nor any laboratory signs of hypercoagulability.

The second recent paper analysed 56 surgical procedures in 40 patients with congenital or acquired haemophilia, who were treated primarily with recombinant activated factor VII [36]. Tranexamic acid was also administered in $64 \%$ of procedures, but the indications for its use are not reported and outcomes in this group of patients are not analysed separately.

Other publications do not substantially improve the evidence base. A structured review of cardiac surgery in people with bleeding disorders including haemophilia, who were treated with factor replacement therapy and antifibrinolytics including tranexamic acid, found a lack of good quality evidence and possible publication bias due to under-reporting of adverse outcomes [37]. A report on the use of tranexamic acid in orthopaedic procedures for people with rare bleeding disorders in general, and von Willebrand disease in particular, included several cases involving tranexamic acid [38.39]. A treatment protocol developed for four patients with severe FXI deficiency and inhibitors included prophylaxis with tranexamic acid and recombinant FVIla [40]. The use of topical tranexamic acid to control perioperative bleeding was described in two women undergoing gynaecological surgery, one of whom had severe FIX deficiency (the other had thrombocytopenia) [41]. A retrospective review described the use of oral tranexamic acid with fibrin glue as part of a protocol to prevent bleeding complications associated with circumcision in boys with haemophilia [42]. In 28 people with mild to moderate inherited bleeding disorders undergoing endoscopy and receiving prophylaxis with tranexamic acid but no factor replacement therapy, there were three cases of bleeding [43].

\section{Menorrhagia}

No meta-analysis of studies of tranexamic acid in the management of menorrhagia in women with inherited bleeding disorders was found.

A recent survey of US haemophilia centres found that $62 \%$ of 1,321 women with von Willebrand disease attending

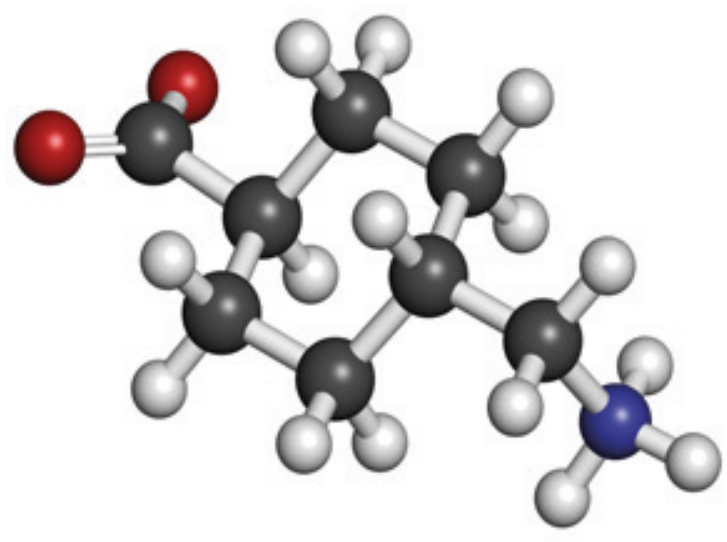

c) Shutterstock Inc.

clinics between 2011 and 2014 had menorrhagia; the most common first-line treatments were combined oral contraceptives, tranexamic acid and desmopressin [44]. A retrospective review of the management of 42 girls with bleeding disorders who had menorrhagia reported that treatment with tranexamic acid, desmopressin, combined oral contraceptive pills, clotting factor concentrate and the levonorgestrel intrauterine system, alone or in combination, reduced menstrual blood flow and improved quality of life scores [45]. A review of the management of menorrhagia in women with inherited bleeding disorders places tranexamic acid among first-line therapies, along with combined oral contraceptives and the levonorgestrel intrauterine system; desmopressin is recommended when these options are inappropriate [46]. A randomised trial of tranexamic acid versus desmopressin included 116 women with menorrhagia and abnormal clotting times, of whom 14 had von Willebrand disease and 22 had 'subnormal coagulation factor level'. Overall, tranexamic acid reduced blood flow more effectively and both treatments improved quality of life scores, but separate analysis by clotting disorder was not reported [47].

\section{Adverse effects}

The adverse effects of tranexamic acid are not well documented in people with haemophilia or other inherited bleeding disorders.

In 2012, the European Medicines Agency reviewed the efficacy and safety of tranexamic acid as part of a review of fibrinolytic drugs, and its findings are largely reflected in European and US labelling [48]. However, it concluded:

'In view of the identified serious limitations of the efficacy data for treatment of haemophilia including the new data and the adverse reactions profile (some of which are serious) associated with the use of TXA [tranexamic acid], the CHMP Committee [Committee for Medicinal Products for Human Use] considers that the benefit risk balance of TXA in this indication is not positive under normal conditions when specific reference is made to haemophilia.'

By contrast, the WHF guideline, also published in 2012, believes the balance of risk and benefit is favourable for 
specific indications (see Appendix 1) [21].

The adverse effects listed by the current UK SPCs for Cyklokapron tablets and injection in the UK are shown in Table 4. This is broadly consistent with the US product labelling, which adds that convulsions are particularly associated with cardiovascular surgery and with inadvertent administration into the neuraxial system [14]. Estimates of the incidence of seizures associated with tranexamic acid in patients undergoing cardiac surgery range from $0-3 \%$ at standard doses and up to 7\% at high doses [49]. Tranexamic acid may increase the excitability of neural networks, an effect that correlates with persistently high postoperative concentrations in cerebrospinal fluid. This raises the possibility of a risk of seizures in people with haemophilia.

Tranexamic acid may also be associated with impairment of mental and/or physical abilities [14]. Although European and US product labelling includes warnings about thromboembolic events $[13,14,17]$, there is no information about how this risk applies to people with bleeding disorders.

\section{Conclusion}

In summary, tranexamic acid may be associated with a relatively narrow range of adverse effects, some of which are potentially serious. Their frequency in patients overall and in people with haemophilia is not clear. This uncertainty led the European Medicines Agency to conclude that the balance of risk and benefit is not positive in people with haemophilia, but this is not consistent with the recommendations of the WHF.

\section{Disclosures}

The author has advised no interests that might be perceived as posing a conflict or bias.

This is an Open Access article distributed under the terms of the Creative Commons Attribution License (http:// creativecommons.org/licenses/by/2.0), which permits unrestricted use, distribution, and reproduction in any medium, provided the original work is properly cited.

\section{References}

1. Nilsson IM. Clinical pharmacology of aminocaproic and tranexamic acids. J Clin Pathol Suppl (R Coll Pathol) 1980;14:41-7.

2. Wikipedia. Tranexamic acid. Available from: https://en.wikipedia.org/ wiki/Tranexamic_acid (accessed 18 March 2016).

3. Grassin-Delyle S, Tremey B, Abe E, et al. Population pharmacokinetics of tranexamic acid in adults undergoing cardiac surgery with cardiopulmonary bypass. Br J Anaesth 2013;111:916-24.

4. Pfizer Ltd. Cyclokapron injection. 5.1 Pharmacodynamic properties. March 2016. Available from: www.medicines.org.uk/emc/ medicine/1489\#PHARMACODYNAMIC_PROPS (accessed 18 March 2016). 5. Wesley MC, Pereira LM, Scharp LA, et al. Pharmacokinetics of tranexamic acid in neonates, infants, and children undergoing cardiac surgery with cardiopulmonary bypass. Anesthesiology 2015;122:746-58.

6 . Hunt BJ. The current place of tranexamic acid in the management of bleeding. Anaesthesia 2015;70 Suppl 1:50-3, e18

7. Ng W, Jerath A, Wąsowicz M. Tranexamic acid: a clinical review. Anaesthesiol Intensive Ther 2015:47:339-50.

8. Sperzel M, Huetter J. Evaluation of aprotinin and tranexamic acid in different in vitro and in vivo models of fibrinolysis, coagulation and thrombus formation. J Thromb Haemost 2007;5:2113-8.

9. Rea CJ, Foley $\mathrm{JH}$, Bevan DH, et al. An in-vitro assessment of tranexamic acid as an adjunct to rFVIII or rFVIla treatment in haemophilia A. Ann Hematol 2014;93:683-92.

10. Tran HT, Sørensen B, Rea CJ, et al. Tranexamic acid as adjunct therapy to bypassing agents in haemophilia A patients with inhibitors. Haemophilia 2014:20:369-75.

11. PharmLine Uganda. Tranexamic acid. Available from: http://www. pharmlineug.com/search.php?drug=Tranexamic\%20Acid (accessed 22 March 2016).

12. Medlndia. Drug "tranexamic acid" price list. Available from: http://www. medindia.net/drug-price/tranexamic-acid.htm (accessed 22 March 2016). 13. Pfizer Ltd. Cyclokapron injection. 6. Pharmaceutical particulars. March 2016. Available from: www.medicines.org.uk/emc/ medicine/1489\#PHARMACEUTICAL_PARTS (accessed 22 March 2016).

14. Pfizer, Pharmacia \& Upjohn. Cyclokapron label. December 2014. Available from: www.accessdata.fda.gov/drugsatfda_docs/ label/2014/019281s033lbl.pdf (accessed 22 March 2016).

15. de Guzman R, Polykratis IA, Sondeen JL, et al. Stability of tranexamic acid after 12 -week storage at temperatures from $-20^{\circ} \mathrm{C}$ to $50^{\circ} \mathrm{C}$. Prehosp Emerg Care 2013;17:394-400.

16. Ferring Pharmaceuticals. Lysteda prescribing information. October 2013. Available from: www.lysteda.com/assets/pi_ferring2013-1f2d77bcb4 2b5738c55afab5280d7e9c.pdf (accessed 22 March 2016).

17. Pfizer Ltd. Cyclokapron tablets. February 2014. Available from: www. medicines.org.uk/emc/medicine/16512 (accessed 22 March 2016).

18. Medlndia. Tranexamic acid - drug information. Available from: www. medindia.net/doctors/drug_information/tranexamic_acid.htm (accessed 22 March 2016).

19. Thall Bastow BD. Teratology and drug use during pregnancy. Medscape. 2016. Available from: http://emedicine.medscape.com/article/260725overview\#a5 (accessed 21 April 2016).

20. Gilad O, Merlob P, Stahl B, et al. Outcome following tranexamic acid exposure during breastfeeding. Breastfeed Med 2014;9:407-10.

21. World Federation of Hemophilia. Guidelines for the management of hemophilia. 2nd ed. 2012. Available from: www1.wfh.org/publications/files/ pdf-1472.pdf (accessed 23 March 2016).

22. van Galen KPM, Engelen ET, Mauser-Bunschoten EP, et al. Antifibrinolytic therapy for preventing oral bleeding in patients with haemophilia or Von Willebrand disease undergoing minor oral surgery or dental extractions. Cochrane Database of Systematic Reviews 2015, issue 12, art. no.: CD011385. doi: 10.1002/14651858.CD011385.pub2. Available from: http://onlinelibrary.wiley.com/doi/10.1002/14651858.CD011385.pub2/full (accessed 21 April 2016)

23. Forbes CD, Barr RD, Reid G, et al. Tranexamic acid in control of haemorrhage after dental extraction in haemophilia and Christmas disease. Br Med J 1972;2:311-3.

24. Lee AP, Boyle CA, Savidge GF, et al. Effectiveness in controlling haemorrhage after dental scaling in people with haemophilia by using tranexamic acid mouthwash. Br Dent J 2005;198:33-8.

25. Nuvvula S, Gaddam KR, Kamatham R. Efficacy of tranexamic acid mouthwash as an alternative for factor replacement in gingival bleeding during dental scaling in cases of hemophilia: a randomized clinical trial. Contemp Clin Dent 2014;5:49-53.

26. Federici AB, Sacco R, Stabile F, et al. Optimising local therapy during oral surgery in patients with von Willebrand disease: effective results from a retrospective analysis of 63 cases. Haemophilia 2000;6:71-7.

27. Franchini M, Rossetti G, Tagliaferri A, et al. Dental procedures in adult patients with hereditary bleeding disorders: 10 years' experience in three Italian hemophilia centers. Haemophilia 2005;11:504-9.

28. Frachon X, Pommereuil M, Berthier AM, et al. Management options for dental extraction in hemophiliacs: a study of 55 extractions (2000-2002). Oral Surg Oral Med Oral Pathol Oral Radiol Endod 2005;99:270-5.

29. Givol N, Hirschhorn A, Lubetsky A, et al. Oral surgery-associated postoperative bleeding in haemophilia patients - a tertiary centre's two decade experience. Haemophilia 2015;21:234-40.

30. Zanon E, Martinelli F, Bacci C, et al. Proposal of a standard approach to dental extraction in haemophilia patients. A case-control study with good results. Haemophilia 2000;6:533-6.

31. Nickles K, Wohlfeil M, Alesci S, et al. Comprehensive treatment of periodontitis in patients with von Willebrand disease. J Periodontol 2010;81:1432-40. 
32. Hewson I, Makhmalbaf $P$, Street A, et al. Dental surgery with minimal factor support in the inherited bleeding disorder population at the Alfred Hospital. Haemophilia 2011;17:e185-8.

33. Coppola A, Windyga J, Tufano A, et al. Treatment for preventing bleeding in people with haemophilia or other congenital bleeding disorders undergoing surgery. Cochrane Database of Systematic Reviews 2015, issue 2, art. no.: CD009961. doi: 10.1002/14651858.CD009961.pub2. Available from: http://onlinelibrary.wiley.com/doi/10.1002/14651858.CD009961. pub2/abstract (accessed 21 April 2016).

34. Valentino LA, Holme PA. Should anti-inhibitor coagulant complex and tranexamic acid be used concomitantly? Haemophilia 2015;21:709-14.

35. Holmström M, Tran HT, Holme PA. Combined treatment with APCC $(F E I B A \circledast)$ and tranexamic acid in patients with haemophilia $A$ with inhibitors and in patients with acquired haemophilia A - a two-centre experience. Haemophilia 2012;18:544-9.

36. Takedani H, Shima M, Horikoshi $Y$, et al. Ten-year experience of recombinant activated factor VII use in surgical patients with congenital haemophilia with inhibitors or acquired haemophilia in Japan. Haemophilia 2015;21:374-9.

37. Rossi M, Jayaram R, Sayeed R. Do patients with haemophilia undergoing cardiac surgery have good surgical outcomes? Interact Cardiovasc Thorac Surg 2011;13:320-31.

38. Siboni SM, Biguzzi E, Pasta G, et al. Management of orthopaedic surgery in rare bleeding disorders. Haemophilia 2014;20:693-701.

39. Siboni SM, Biguzzi E, Solimeno LP, et al. Orthopaedic surgery in patients with von Willebrand disease. Haemophilia 2014;20:133-40.

40. Livnat T, Tamarin I, Mor Y, et al. Recombinant activated factor VII and tranexamic acid are haemostatically effective during major surgery in factor XI-deficient patients with inhibitor antibodies. Thromb Haemost 2009:102:487-92.

41. Sarris I, Arafa A, Konaris L, et al. Topical use of tranexamic acid to control perioperative local bleeding in gynaecology patients with clotting disorders: two cases. Haemophilia 2007:13:115-6.

42. Yilmaz D, Akin M, Ay Y, et al. A single centre experience in circumcision of haemophilia patients: Izmir protocol. Haemophilia 2010;16:888-91.

43. Davis A, Walsh M, McCarthy $P$, et al. Tranexamic acid without prophylactic factor replacement for prevention of bleeding in hereditary bleeding disorder patients undergoing endoscopy: a pilot study. Haemophilia 2013;19:583-9.

44. Ragni MV, Machin N, Malec LM, et al. Von Willebrand factor for menorrhagia: a survey and literature review. Haemophilia 2016 Feb 4. doi: 10.1111/hae.12898 [Epub ahead of print].

45. Chi C, Pollard D, Tuddenham EG, Kadir RA. Menorrhagia in adolescents with inherited bleeding disorders. J Pediatr Adolesc Gynecol 2010;23:21522.

46. Rodeghiero F. Management of menorrhagia in women with inherited bleeding disorders: general principles and use of desmopressin. Haemophilia 2008;14 Suppl 1:21-30.

47. Kouides PA, Byams VR, Philipp CS, et al. Multisite management study of menorrhagia with abnormal laboratory haemostasis: a prospective crossover study of intranasal desmopressin and oral tranexamic acid. $\mathrm{Br} \mathrm{J}$ Haematol 2009;145:212-20.
48. European Medicines Agency. Assessment report. Antifibrinolytics containing aprotinin, aminocaproic acid and tranexamic acid. Tranexamic acid. EMA/680967/2012. October 2012. Available from: http://www. ema.europa.eu/docs/en_GB/document_library/Referrals_document/ Antifibrinolytic_medicines/WC500153603.pdf (accessed 21 April 2016).

49. Lecker I, Wang DS, Whissell PD, et al. Tranexamic acid-associated seizures: causes and treatment. Ann Neurol 2016;79:18-26.

50. Okamoto S, Okamoto U. Amino-methyl-cyclohexane carboxylic acid: AMCHA. A new potent inhibitor of fibrinolysis. Keio J Med 1962;11:105-15. Available from: https://www.jstage.jst.go.jp/article/ kjm1952/11/3/11_3_105/_pdf (accessed 21 April 2016).

\section{Appendix 1}

Summary of World Hemophilia Federation (WHF) guideline recommendations for the use of tranexamic acid [21]

\section{General}

The comprehensive care team should have access to appropriate clotting factor concentrates, either plasmaderived or recombinant, and other adjunct haemostatic agents, such as desmopressin (DDAVP) and tranexamic acid, where possible.

\section{Adjunctive management}

- Antifibrinolytic drugs (e.g. tranexamic acid, epsilon aminocaproic acid) are effective as adjunctive treatment for mucosal bleeds and dental extractions.

\section{Dental therapy}

Dental extraction or surgical procedures carried out within the oral cavity should be done with a plan for haemostasis management, in consultation with the haematologist. (Level 3)

- Tranexamic acid or epsilon aminocaproic acid (EACA) is often used after dental procedures to reduce the need for replacement therapy. (Level 4)

\section{Other pharmacological options [other than factors and plasma-derived agents]}

- Regular treatment with tranexamic acid alone is of no value in the prevention of haemarthroses in haemophilia. (Level 4)

- It is valuable, however, in controlling bleeding from skin and mucosal surfaces (e.g. Oral bleeding, epistaxis, menorrhagia). (Level 2)

Table 5: Results of tranexamic acid use in people undergoing dental extraction

\begin{tabular}{|l|l|l|}
\hline Endpoint & Placebo & Tranexamic acid \\
\hline Mean number (range) of roots extracted & 5.5 & 6.9 \\
& $(2-12)$ & $(2-22)$ \\
\hline Mean (range) blood loss per patient $(\mathrm{ml})$ & 84.1 & $61.2^{\star}$ \\
& $(4-323)$ & $(1-749)$ \\
\hline Mean (range) blood lost per root extracted $(\mathrm{ml})$ & 15.3 & 8.9 \\
& $(05-64)$ & $(05-38.6)$ \\
\hline Mean number (range) of units of replacement therapy per root extracted & $617(0-15,800)$ & 30 and 65 in two patients \\
\hline Mean fall in haemoglobin $(\mathrm{g} / 100 \mathrm{ml})$ & 1.4 & 0.3 \\
\hline Mean fall in packed cell volume $(\%)$ & 5.0 & 0.9 \\
\hline
\end{tabular}

* $p<0.025$ 
- Tranexamic acid is particularly valuable in the setting of dental surgery and may be used to control oral bleeding associated with eruption or shedding of teeth. (Level 4)

- Tranexamic acid may be given alone or together with standard doses of coagulation factor concentrates. (Level 4)

- Tranexamic acid should not be given to patients with FIX deficiency receiving prothrombin complex concentrates, as this will exacerbate the risk of thromboembolism. (Level 5)

- If treatment with both agents is deemed necessary, it is recommended that at least 12 hours elapse between the last dose of APCC and the administration of tranexamic acid. (Level 5)

- In contrast, thromboembolism is less likely when tranexamic acid is used in combination with rFVIla to enhance haemostasis. (Level 4)

\section{Acute gastrointestinal haemorrhage}

EACA (epsilon aminocaproic acid) or tranexamic acid may be used as adjunctive therapy for patients with FVIII deficiency and those with FIX deficiency who are not being treated with prothrombin complex concentrates.

\section{Oral haemorrhage}

Local treatments must be considered to treat the haemorrhage. These may include:

- direct pressure on the area using a damp gauze swab, maintained for at least 15 minutes

- sutures to close the wound

- application of local haemostatic agents

- antibiotics, especially in gingival bleeding due to poor oral hygiene

- use of EACA or tranexamic acid as a mouthwash

- Antifibrinolytic agents should not be used systemically in patients with FIX deficiency who are being treated with large doses of prothrombin complex concentrates, or in patients with inhibitors being treated with activated prothrombin complex concentrates (APCC). (Level 4)

- Oral EACA or tranexamic acid should be used if appropriate. (Level 4)

\section{Epistaxis}

EACA or tranexamic acid applied locally in a soaked gauze is helpful.

\section{Appendix 2}

Summary of results reported in Forbes, et al. 'Use of tranexamic acid in control of haemorrhage after extraction of teeth in haemophilia and Christmas disease,' British Medical Journal 1972;2:311-3.23

The trial is based on data collected in the 1960s and involved people with haemophilia $A(n=20)$ or $B(n=8)$ who were undergoing dental extraction at the General Hospital in Birmingham; haemophilia was severe in 15, moderate in 11 and mild in two. Inhibitor status was not reported. Exclusion criteria were a history of haematuria in the previous four weeks or the presence of red cells in a fresh urine sample. Participants were randomised to receive placebo or tranexamic acid $1.0 \mathrm{~g}$ three times daily from two hours before surgery and continued for five days; one hour before extraction, they also received a dose of Factor VIII or IX equivalent to the content of $1 \mathrm{~L}$ human plasma. The results are summarised in Table 5.

Some patients underwent extensive surgery. Two patients treated with tranexamic acid received postoperative infusions of plasma or plasma concentrate, one of whom had 22 extractions. In the placebo group, 11 required multiple infusions over the five postoperative days; of five who did not, all had mild or moderate haemophilia. 